\title{
أثر قطعية المباحث اللفظية على المنهج المعرفي الأصولي: الرازي والثاطبي نموذجان
}

\author{
AL-RĀZĪ AND AL-SHĀṬIBĪ ON THE IMPACT OF \\ PHILOSOPHY ON THE DEFINITIVE AND HYPOTHETICAL \\ ASPECTS OF THE JURISTIC DEDUCTIVE METHOD
}

\section{‘Ammar bin Abdullah Naseh`Ulwan}

Faculty of Shariah \& Law. Universiti Islam Sultan Sharif Ali (UNISSA). Bandar Seri Begawan. Brunei Darussalam

Email: amar500000@ hotmail.com

\begin{abstract}
Khulasah
Para ulama sepakat menerima kaedah epistemologi shariah sebagai prinsip perundangan Islam (Ușūl alFiqh). Setiap aliran pemikiran mempunyai prinsip perundangan Islam tersendiri sebagai kriteria epistemologi. Oleh itu, sebahagian besar mazhab Islam yang berpengaruh ke atas pemikiran Islam mempunyai prinsip-prinsip perundangan Islam yang tersendiri sebagai satu kaedah epistemologi; dan prinsip-prinsip perundangan Islam tersebut mewakili kaedah epistemologi aliran pemikiran yang berbeza dalam kalangan umat Islam. Falsafah mempunyai pengaruh ke atas pembangunan dan pembentukan kaedah epistemologi ini terutamanya dalam mengklasifikasikan sumber asal perundangan Islam sama ada yang bersifat definitif (muktamad) mahupun yang bersifat hipotesis deduktif. Para ahli falsafah telah berpendapat bahawa deduksi terhadap aspek kemuktamadan (definitif) hanyalah suatu bentuk kesimpulan rasional dan bukannya penyataan yang bersifat empirik. Berdasarkan pengklasifikasian tersebut, rumusan hipotesis dapat dicapai melalui kaedah deduktif. Al-Rāzi didapati telah mempelopori perbahasan berkenaan hipotesis deduktif dalam karyanya al-Mahșūl. Beliau berpendapat bahawa aspek definitif tidak sekadar wujud dalam perbincangan
\end{abstract}


literal. Walau bagaimanapun, al-Shātibi merupakan pemikir yang pertama memperkenalkan perbincangan ini dalam al-Muwāfaqāt. Beliau berhujah bahawa "prinsip-prinsip perundangan Islam" adalah muktamad dan pengetahuan agama adalah menyamai pengetahuan rasional. Beliau juga berpendapat bahawa aspek definitif prinsip-prinsip perundangan Islam adalah terhasil daripada kaedah falsafah yang dipanggil induksi. Kaedah induksi ini boleh dimanfaatkan dalam hal perundangan, serta penghujahan terhadap larangan berlakunya perbezaan yang hanya dihadkan kepada beberapa perkara ijmak sahaja. Justeru, hal ini menjadikan perbezaan pandangan sebagai suatu yang wajar dalam setiap perkara perundangan.

Keywords: al-Shāțibi, al-Rāzí, definitif, hipotesis, metode deduktif.

Abstract
Muslim scholars agreed to accept an epistemological
shari ah method as the "principles of Islamic
jurisprudence" (Ușul al-Fiqh). Each school of thought
has its own Islamic legal principles as the
epistemological criteria. Therefore, the most of
influential Islamic sects on the Islamic thought have the
principles of Islamic law as their own epistemological
method; and the principles of Islamic law represent the
epistemological method of the different schools of
thought among Muslims. Philosophy has an influence
on the development and formulation of this
epistemological method, particularly in classifying the
definitive (final) or even hypothetical deductive in the
original sources of Islamic law. The philosophers have
argued that the deduction of the finality (definitive) is a
form of rational inferences and is not empirical
statements. Based on this classification, a hypothesis
formulation can be achieved through the deductive
methods. Al-Rāzi pioneered the debate on the
hypothetical deduction in his book, al-Mahșül. He
argued that the definitive aspect does not merely exist in
the literal discussions. However, al-Shātibi, a thinker,


who was the first person, introduced this discussion in al-Muwāfaqāt. He argued that "the principles of Islamic law" are definitive and the religious knowledge is equivalent to the rational knowledge. He thus believed that the definitive aspects of the principles of Islamic law are derived from the philosophical method called induction. This induction method can be benefitted in legal matters, as well as in arguments in the prohibition of the differences that are only limited to a few matters of ijma`. Therefore, it makes a disagreement of opinions is justifiable in every legal matter.

Keywords: al-Shātịbi, al-Rāzì, definitive, hypothetical, deductive method

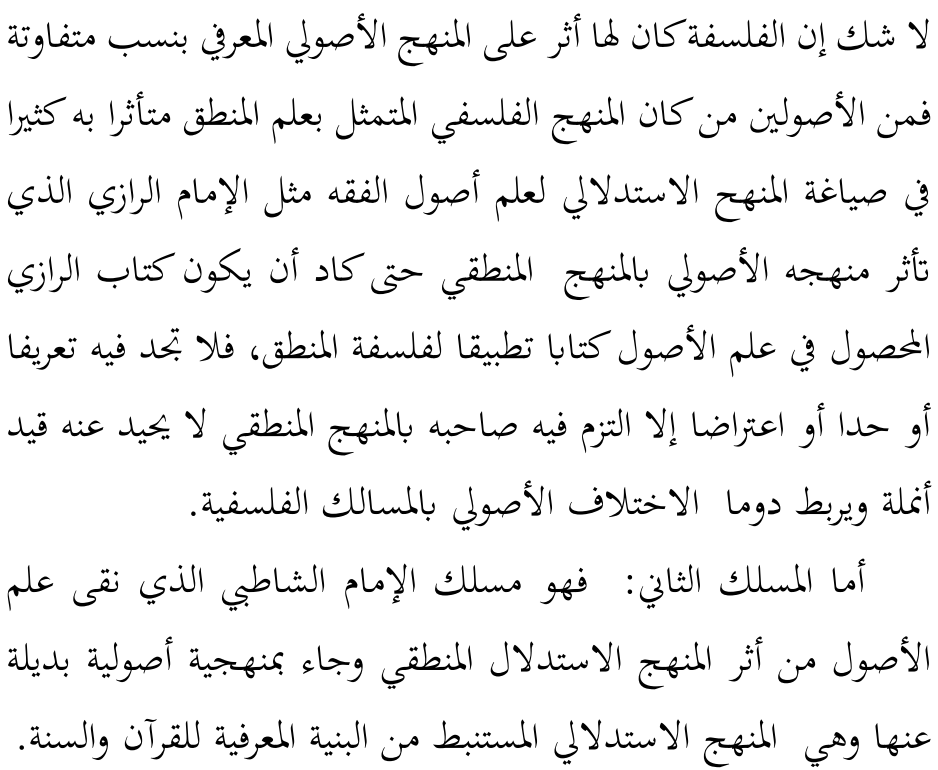




\section{ملامح من منهجية الرازي في كتاب الخصصول:}

\section{غلبة المسلك الاستدلالي الفلسفي على المنهج الاستدلالي الأصولي}

إن الناظر في كتاب المحصول يجد بالضرورة غلبة المنهجية الجدلية المنبثقة من علم المنطق في نقد التعاريف والحدود والاعتراضات وغلبة الاستدلال العقلي في تأصيل مسائل علم الأصول على الاستدلال النصي وأكثرما يتضح هذا المسلك عند الإمام الرازي في باب الأمرولكن هل مليل منهجية الاصنية

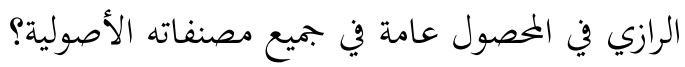
قد يحسب الناظر إن المنهج الذي سلكه الإمام الرازي في محصوله

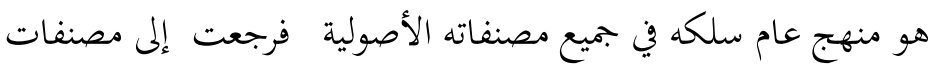

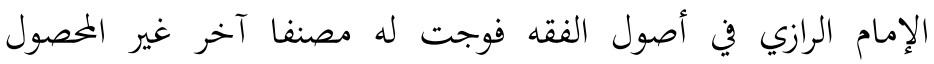

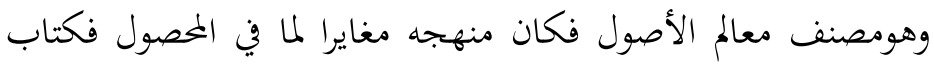

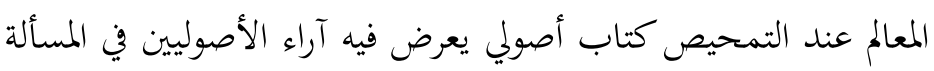

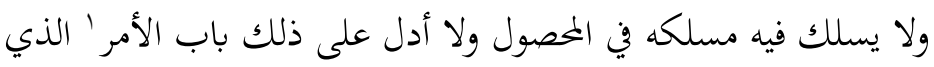

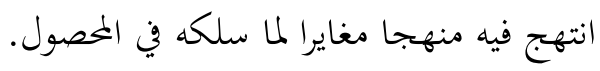

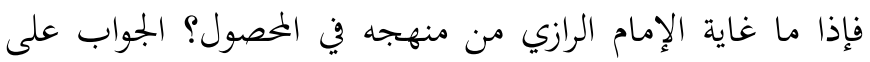

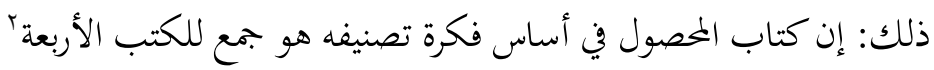
لعل الرازي أراد بذلك إظهار قدرته الجدلية مقارنة مع فحول الأصوليين

' - ينظر الرازي ، فخر الدين محمد بن عمر، المعالم في علم أصول الفقه، المققان، علي

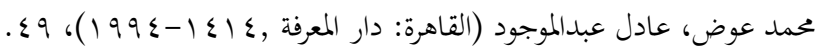
r بينظر الرازي، فخر الدين محمد بن عمر.المحصول، المحقق، طه جابر العلواني (بيروت:

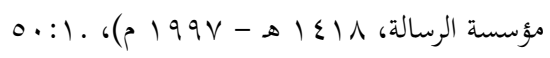


السابقين و -أيضا- ربما أراد بيان تفوق مدرسة المتكلمين التي ينتمي إليها الرازي من حيث المنهجية المنطقية التي تنتقد الحدود والتعاريف والحجج بالبراهين المنطقية الفلسفية لا بالتعصب المذهبي فمدرسة المتكلمين والأحناف قد تكونت ملامح كل مدرسة منهما وظهر أنصار لكل مدرسة وطغى التعصب الأصولي لمما مثلما طغى في الفروع الفقهية بخاصة مذهبي الحنفية والشافي بحكم التصاقب الجغرافي والاختلاف المنهجي الأصولي بين المدرستين فتجد الرازي دوما يشير بفخر إلى مدرسة المتكلمين التي ينتمي إليها الرازي عندما ينتقد الحدود والتعاريف الأصولية متقيدا بكامل المنهجية المنطقية في نقد التعاريف والحدود، فيكون تفوق مدرسة المتكلمين الشافعية على مدرسة الفقهاء الحنفية من ناحية أن منهجهم قد عضد بالأسس المنطقية والمسالك الفلسفي.

\section{الميزة العلمية لمنهجية الرازي في الحصول}

لعل من مزايا هذا المنهج تنقيح عقلية الأصولي لصنع الملكة النقدية في نقد التعاريف والحلدود واستعمال الألفاظ المحددة الجامعة المانعة.فمن أراد تكوين تلك العقلية النقدية فلا أجد له كتابا تطبيقيا أفضل من كتاب المحصول فالرازي قد أظهر فيه قدرات جدلية فائقة قدرات فحول الأصوليين من قبله. 
سسبب غلبة النزعة الجدلية عند الإمام الرازي في علمي الأصول والتفسير أرى أن النزعة المنطقية في منهجية الاستدلالية قد سيطرت على مدرسة

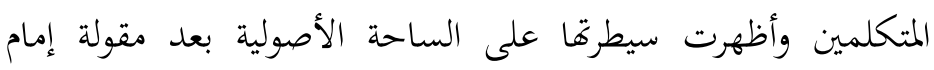

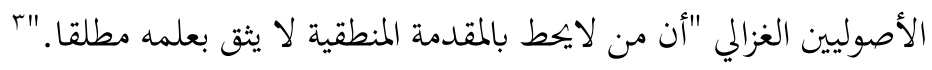

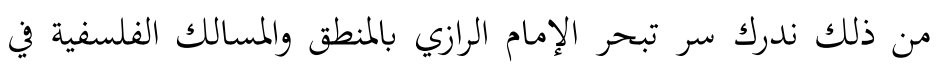

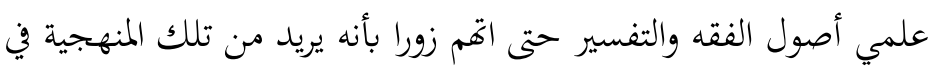

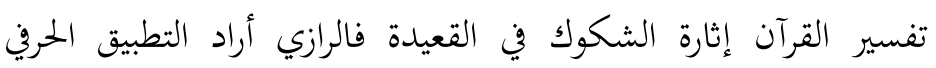

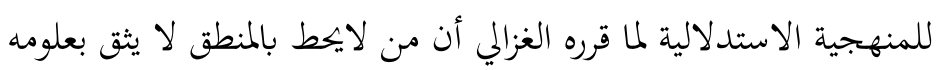
أصلا.

أثر المنهج الفلسفي على تصنيف أبواب أصول الفقه عند الرازي

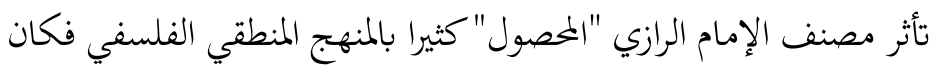
ترتيب الرازي لأبواب أصول الفقه على نحو فلسفي بحت، فأول ما بدأ

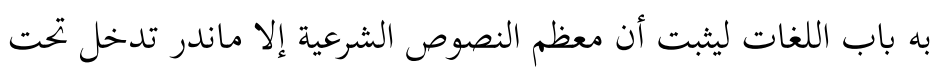

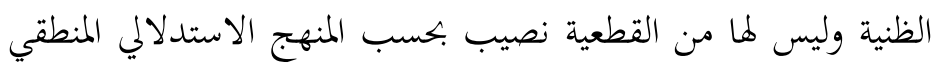
فقال: ".. ثم هذه الأقوال والأفعال قد يحتاج إلى التمسك بها من لم يشاهد

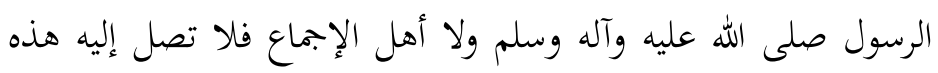

$$
\begin{aligned}
& \text { r - - ينظر الغزالي ، محمد بن محمد .المستصفى ، المحقق: محمد عبدالسلام (بيروت: دار }
\end{aligned}
$$

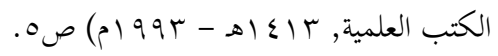


الأدلة إلا بالنقل فلا بد من البحث عن النقل الذي يفيد العلم والنقل

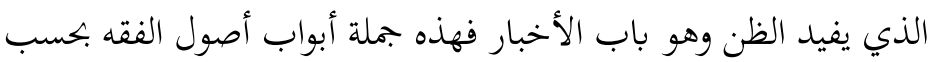

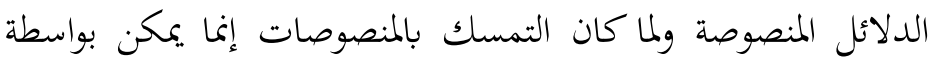
اللغات فلا بد من تقديم باب اللغات على الكل.. فهذه أبواب أصول

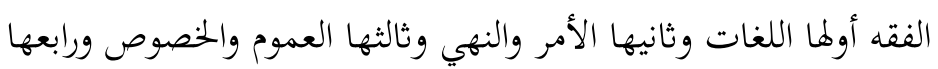

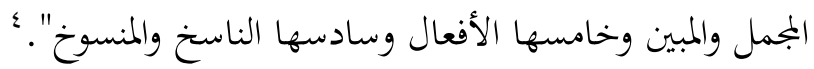

\section{الاعتراضات العشرة على قطعية النصوص}

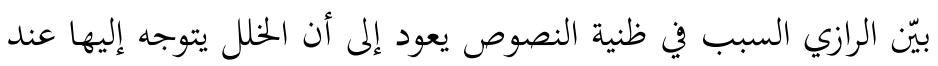

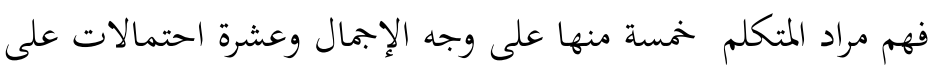
وجه التفصيل قال:

".. التعارض الحاصل بين أحوال الألفاظ اعلم أن الخنلل الحاصل في

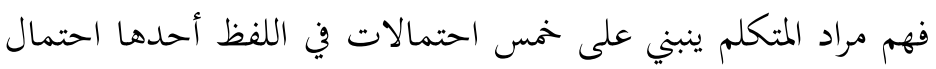
الاشتراك وثانيها احتمال النقل بالعرف أو الشرع وثالثها احتمال المجاز ورابعها احتمال الإضمار وخامسها احتمال التخصيص..." واعلم أن التعارض بين هذه الاحتمالات يقع في عشرة أوجه لأنه

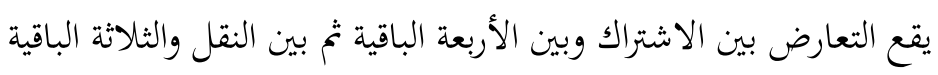

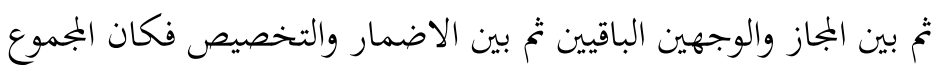
عشرة.."

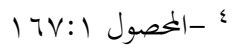

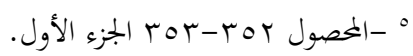


فنظرة لما قاله الرازي نجد أنه جعل هذه الاحتمالات متوجبة في كل النصوص لكن منهج الشاطبي في تواتر المعنوي-الذي سوف هلئ مأتي ذكره

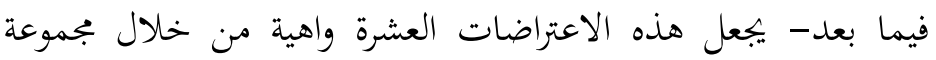
نصوص تفيد معنى واحد فلا يمكن أن يتطرق إليها الاحتمالات العشرة.

\section{النصوص الشرعية إمارات وليست أدلة}

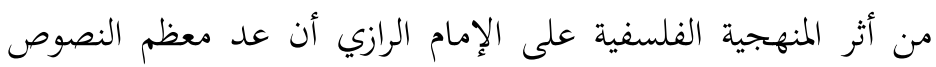

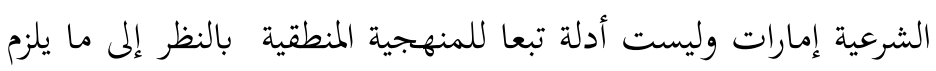
عن التصديقات قال:

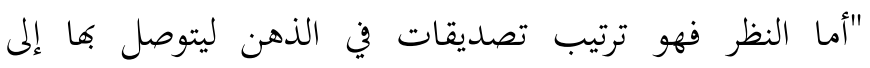
تصديقات أخر والمراد من التصديق اسناد الذهن أمرا إلى أمر بالنفي أو لتوني

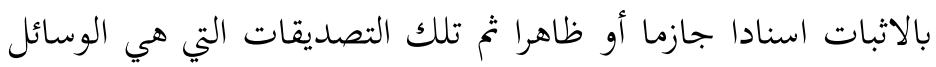

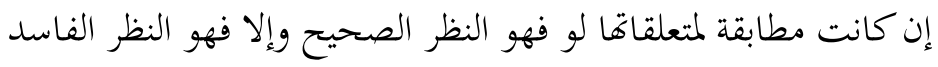

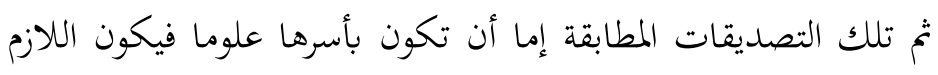

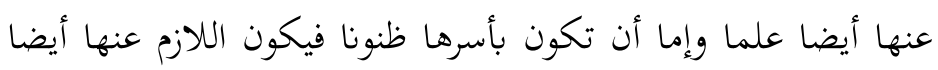

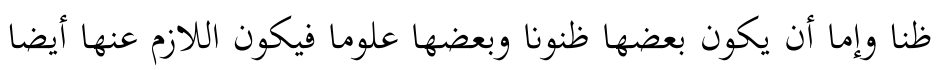
ظنا لأن حصول النتيجة موقوف على حصول جميع المقدمات فإذا كان

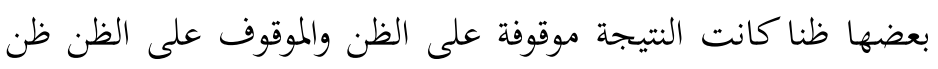
فالنتيجة ظنية لا محالة.." 
علق طه جابر العلواني محقق كتاب المحصول على رأي الرازي السابق

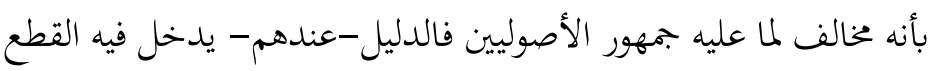
والظن لأغم عرفوا الدليل : ما يمكن التوصل-بصحيح النظرفيه-إلى الى فئل

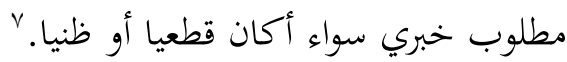

\section{إنكار الرازي على منهج الأصوليين في حجية خبر الآحاد دون حجية}

\section{دلالة اللغة}

لما كان المنهج الفلسفي غالبا على منهج الرازي دفعه ذلك المنهج إلى نقد

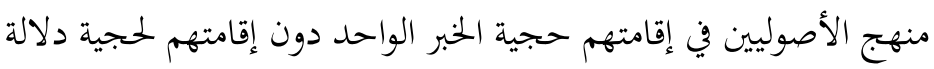

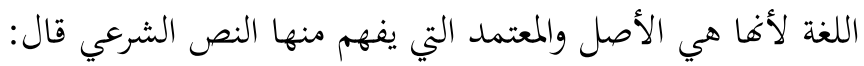

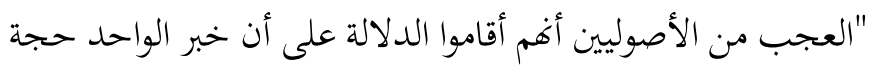

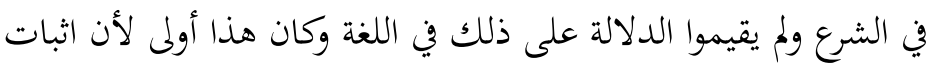

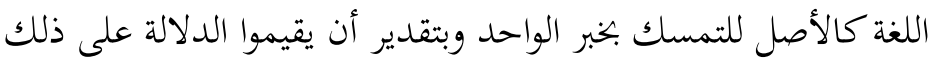

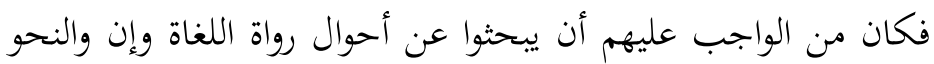

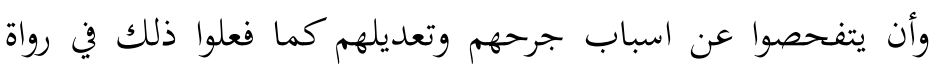
الأخبار لكنهم تركوا ذلك بالكلية مع شدة الحاجة إليه فإن اللغة والنحو

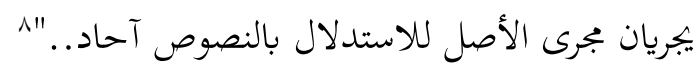


هل نظرية ظنية اللغات"الأدلة" مطردة عند الرازي في جميع المباحث الأصولية؟

أكد الإمام الرازي على نظريته في مواضع شتى حين يتطلب القول بقطعية

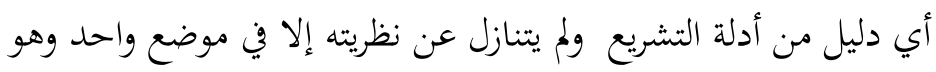

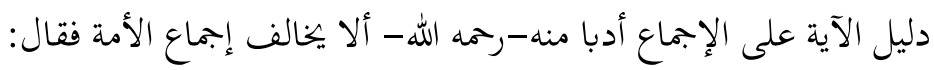

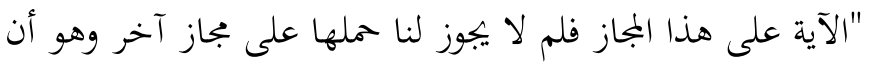

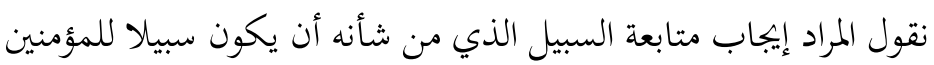

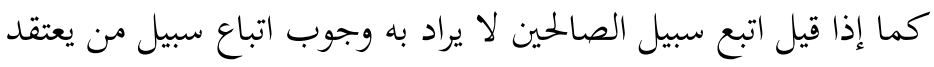

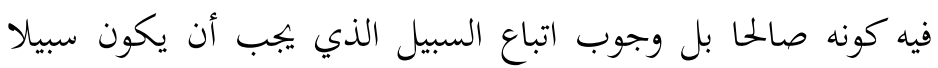
للصالحين سلمنا دلالة الآية على كون الإجماع حجة لكن لكن دلالة قطيعة لكابل

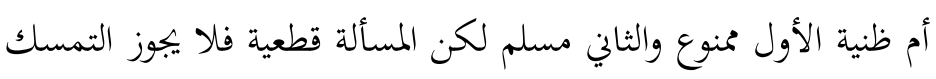

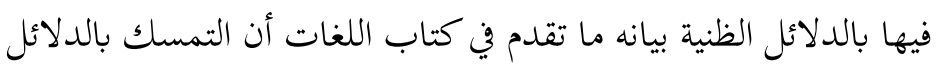

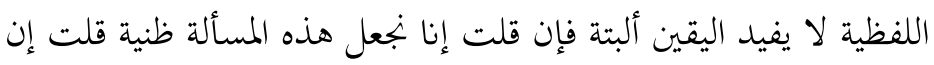

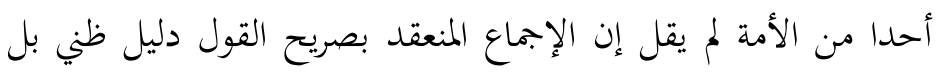

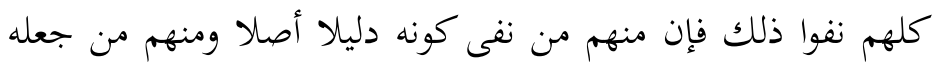

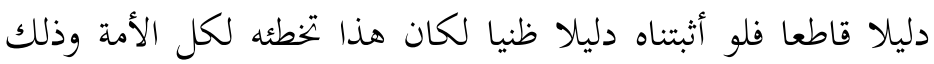
يقدح في الإجماع". 9فالرازي هنا لم يترك نظريته بظنية عن اقتناع منهجي، بل تأدبا منه ألا يخطأ الأمة فيما ذهبت إليه. 
هل الرازي يقول بإمكانية قطعية الأدلة الشرعية إذا تعاضد الدليل

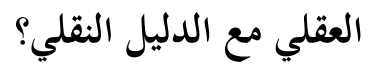
فيما سبق هل نقول بتعذر القول بقطعية الأدلة الشرعية بحسب نظرية الشعبي

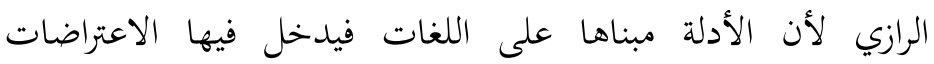

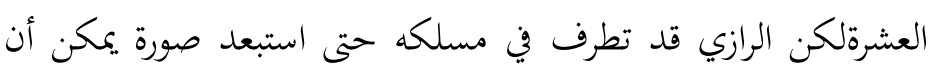

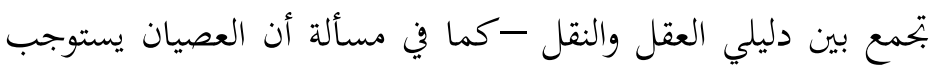

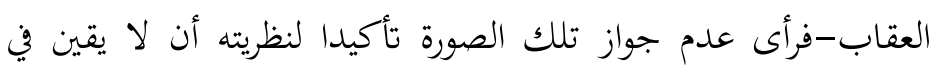

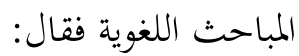

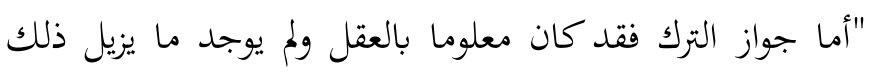

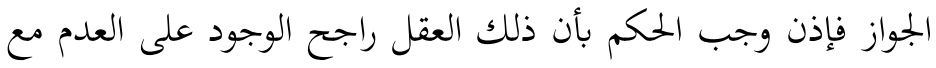
كونه جائز الترك ولا معنى للندب إلا ذلك والجواب عن الأول أن نقول لم لا يجوز أن يعرف ذلك بدليل مركب من النقل والعقل مثل قولنا تارك

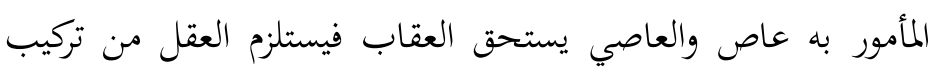

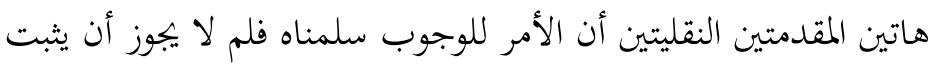

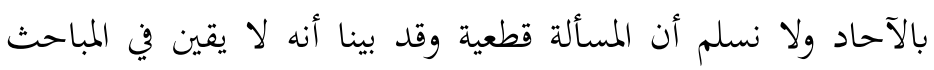

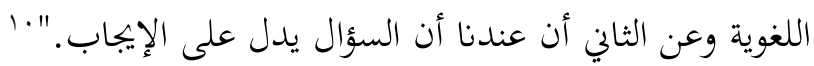

\section{موقف الثاطبي من منهجية الرازي}

يتمايز الإمام الشاطبي بالأدب الجمم مع مخالفيه فمن منهجه فراي في النقد أنه

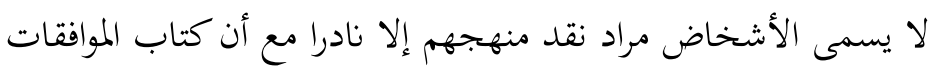


كان من غايات تأليفه إيجاد منهجية استدلالية منبعها المعرفة الإسلامية مع ذلك استقرأت كتاب الموافقات فوجدت أن أكثر ما وجه إليه النقد من الأصوليين هو الإمام الرازي تارة لمنهجيته وأحيانا في نقد ما ذهب إليه من تعاريف وحدود على وفق منهجيته الفلسفية. فمثال على نقد الإمام الشاطبي للرازي لمنهجيته حين قرر الإمام الشاطبي في المقدمة الرابعة أن كل مسألة لا يبنى عليها عمل فوضعها في أصول الفقه عارية فنقد الرازي إدخال مسألة مخاطبة الكفار بالفروع الفقهية.

أما نقد الإمام الشاطبي للرازي فيما ذهب إليه الرازي من آراء وتعاريف فكثير منها نقده لتعريف الرخصة حيث قال: ".. وهو: هل الوجوب والتحريم أو غيرها راجعة إلى صفة الأعيان اه أو إلى خطاب الشارع؟ وكمسألة تكليف الكفار بالفروع r عند الفخر الرازي، وهو ظاهر؛ فإنه لا ينبني عليه عمل، وما أشبه ذلك من المسائل التي فرضوها مما لا ثمرة له في الفقه.لا يقال: إن ما يرجع الخلاف فيه إلى الاعتقاد

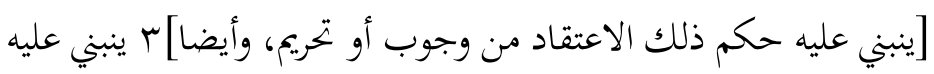
عصمة الدم والمال، والحلكم بالعدالة أو غيرها من الكفر إلى ما دونه، وأشباه ذلك، وهو من علم الفروع؛ لأنا نقول: هذا جار في علم الكلام في جميع مسائله؛ فليكن من أصول الفقه. أما التمثيل لنقد الشاطبي للرازي فيما ذهب إليه فمنه نقده "إطلاق القول بأن الأصل في المنافع الإذن، وفي المضار المنع، كما قرره الفخر 
الرازي" '، إذ لا يكاد يوجد انتفاع حقيقي ولا ضرر حقيقي، وإنما عامتها أن تكون إضافية.والمصالح والمفاسد إذا كانت راجعة إلى خطاب الشارع -وقد علمنا من خطابه أنه يتوجه بحسب الأحوال والأشخاص والأوقات حتى يكون الانتفاع المعين مأذونا فيه في وقت أو حال أو بحسب لتوبه شخص. " 1"

\section{المنهج الاستدلالي الأصولي عند الإمام الشاطبي}

يبدو أن الإمام الشاطبي قد أقلقه تسلط المنهج الاستدلالي المنطقي الذي قاده الرازي على المنهجية الأصولية فمدرسة المتكلمين لم يقتصر أنصارها على أصوليين الشافعية بل امتد أنصارها إلى أصوليين المالكية والحنابلة فهذه المنهجية من مثالبها أها قد أضعفت الثقة بأصول الفقه فقلبته من القطعية إلى الظنية فعمل الإمام الشاطبي على تنقية الاستدلالية الأصولية مما علق بها من آثار المنهجية المنطقية فأصبغ عليها القطع وبين أن الأصول الفقهية لا تقل قطعية عن الأصول العقلية فعقد مقدمات لكتابه الفذ "الموافقات" فهذه المقدمات ماهي عند الدراسة والتمحيص إلا رسما متكاملا لمنهجية استدلالية قطعية منبعها مصادر التشريع الإسلامي كما- سيتبين - عند عرض هذه المقدمات.

والمقدمات التي عقدها الإمام الشاطبي في بداية كتاب الموافقات هي اتباع نفس مسار التصنيف الذي سار عليه الإمام الرازي لكن شتان في 
المحتوى فمقدمات الرازي جاءت لتصبغ الظنية في علم أصول الفقه بينما جاءت مقدمات الشاطبي لتضفي القطعية على علم أصول الفقه.

\section{المقدمة الأولى: الأدلة على قطعية أصول الفقه}

كان تناول الشاطبي لمقدمة الأولى بذكر الأدلة الرئيسة المقررة لقطعية أصول الفقه وإن قطعية أصول الفقه ليست ببدع أتى بها الشاطبي ، بل هي الأصل المتبع عند فحول الأصوليين المتقدمين، وإن القول بظنية الأصول طارئ عند المتأخرين بسبب منهج المتأخرين في تناول أدلة أصول الفقه. وابتدأ الشاطبي هذه القاعدة بالجزم بقطعية أصول الفقه بقوله "أن أصول الفقه في الدين قطعية لا ظنية،" مدلاًً على ذلك بثلاثة أدلة: الدليل الأول: أن أصول الفقه أسسها وقواعدها مستمدة من كليات الشريعة ومسائلها القائمة على القطعية. ودلل الشاطبي لما ذهب إليه بطريق السبر والتقسيم لأصول الفقهية فالأصول القطعية لديه إما أن ترجع تلك الأصول إلى أصول عقلية -وهي أصول قطعية - أو أن ترجع إلى الاستقراء الكلي من أدلة الشريعة، وعلى هذا السبر لا بدّ أن تكون أصول إصول الفقه قطعية لأن الأصول الفقهية لا تتكون إلا بمجموعهما والمؤلف من القطعيات قطعي لا محالة. الدليل الثاني: "وهو دليل استنتاجي مكمل للدليل الأول وهو" أنه لو كانت أصول الفقه ظنية لم تكن راجعة إلى أمر عقلي ولا إلى كليات الشريعة وتعليل ذلك: أن الظن لا يقبل في العقليات ولا يتعلق أيضاً بكليات الشريعة لأن الظن لا يتعلق بالكليات" الضروريات والحاجيات 
والتحسينيات "وإنما يتعلق بالظنيات لأن لو جاز تعلق الظن بكليات

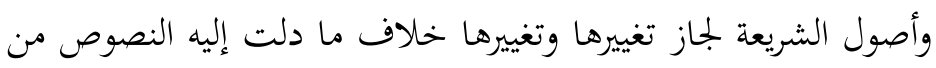

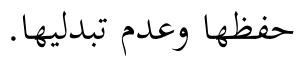

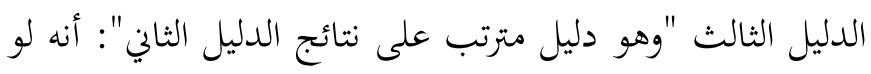

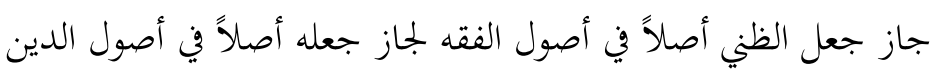

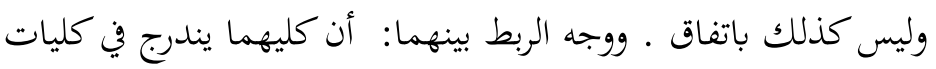

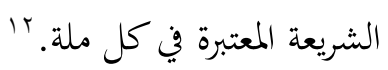

نلاحظ على الأدلة الثلاثة التي استدل بها الشاطبي على قطعية

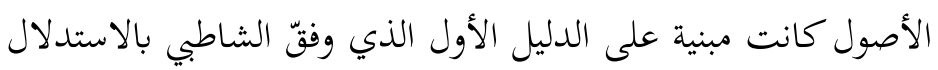

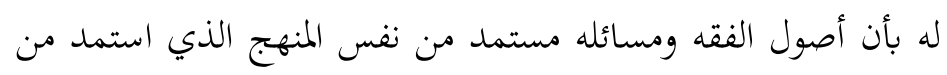
كليات الشريعة التى لا يختلف فيها أحد من الأصوليين على قطعيتها.

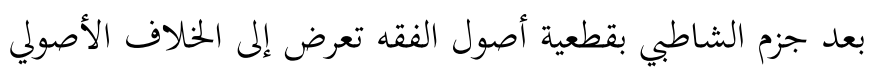

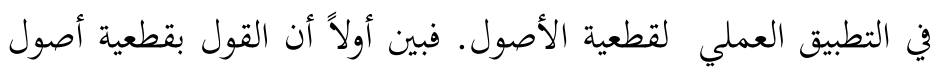

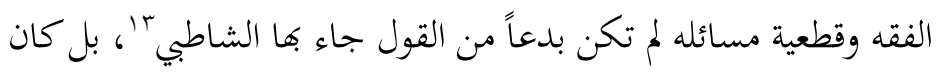

r' -ا: الشاطبي، أبو إبراهيم بن إسحاق، الموافقات في أصول الشريعة، الجزء الأول (دط)

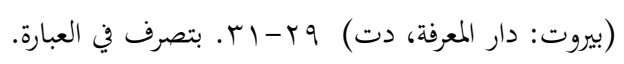

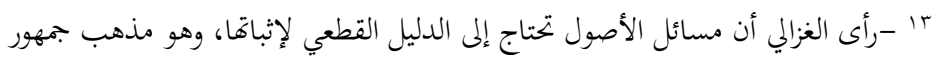

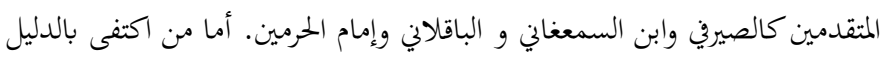

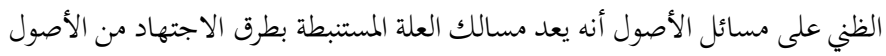

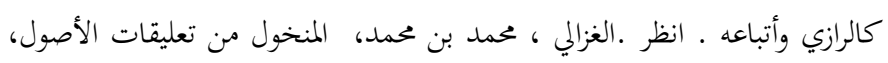

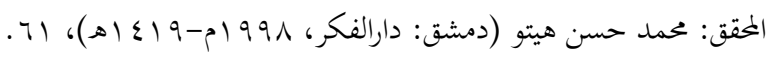


كان القول به الأساس عند سلاطين الأصوليين المتقدمين من أمثال إمام

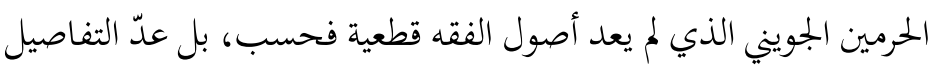

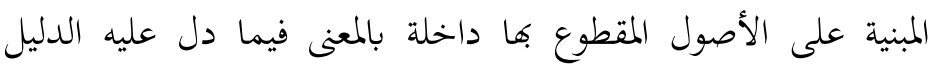
القطعي.

لكن ما مكمن الخلاف بين الشاطبي والأصوليين في قطعية أصول

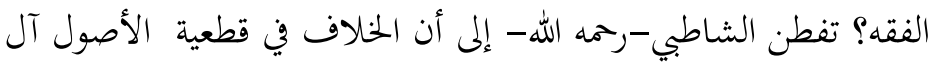
إلى التطبيق العملي لا النظري وتتجلى الإشكالية في المنهجية العلمية في

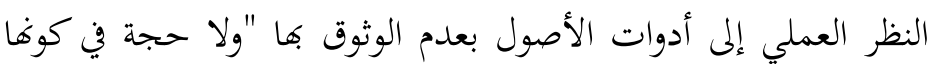
غير مرداة لأنفسها، حتى يستهان بطلب القطع فيها، فإنها حاكمة على إنى

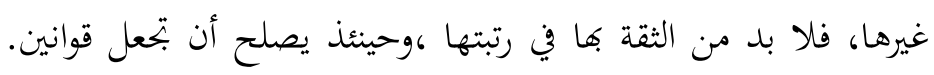

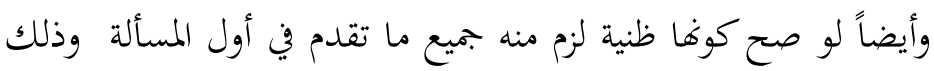

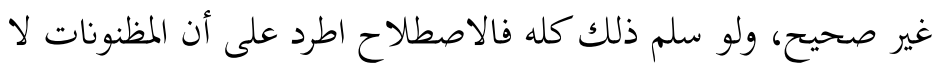

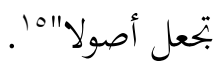

؛' - الموافقات ا: اب ـ ـ بحثت في البرهان عن مراد الشاطبي بأن الجويني أدخل التفاصيل

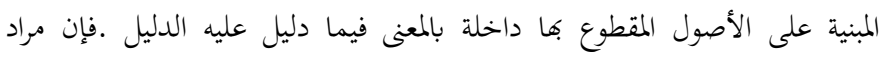

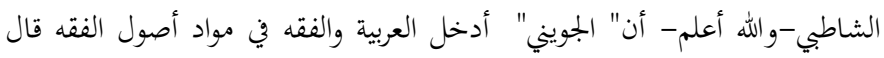

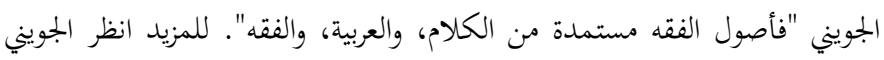

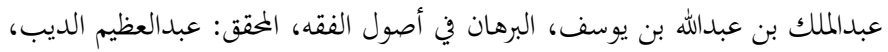

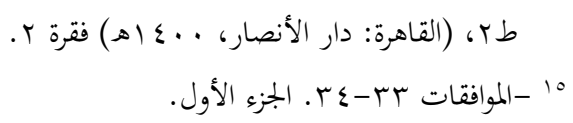


فإذاً لا بد من منهجية جديدة تأخذ بعين الاعتبار منهج القطع

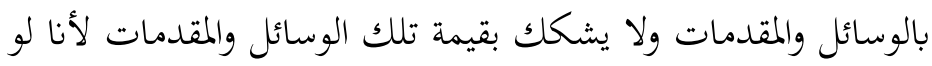

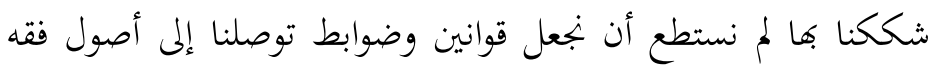

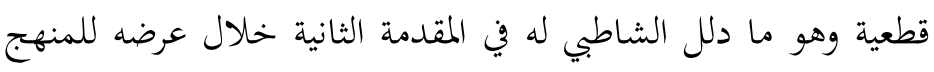

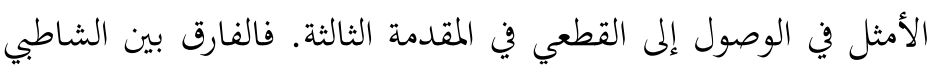

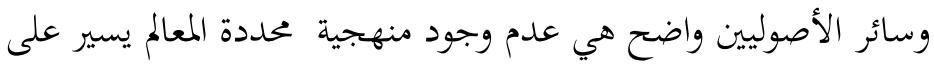

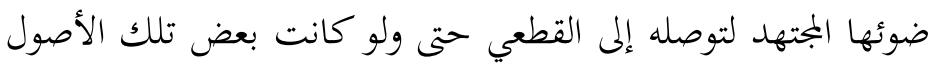

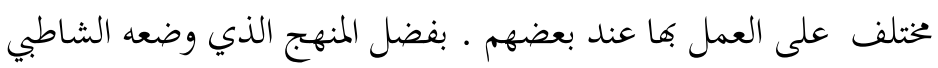
يستطيع المتهد الوصول بها إلى القطع.

\section{المقدمة الثانية :القطعية في مقدمات علم الأصول}

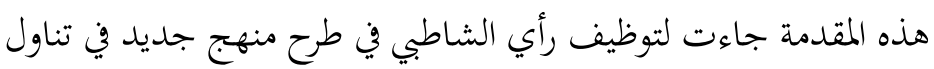

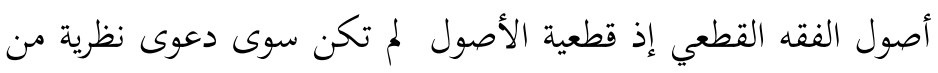

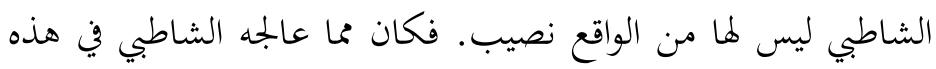
المقدمة ما يشمل دعوته في دخول القطعي من أصول الفقه ومالا يشمل.

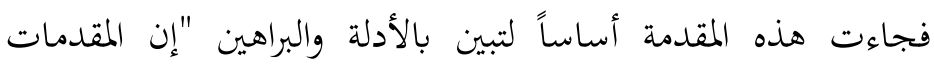

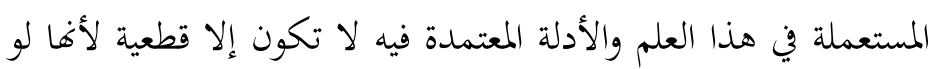
كانت ظنية لم تفد القطع في المطالب المختصة به".

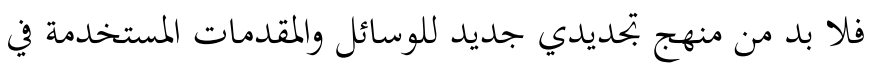
هذا العلم وعدم الاعتماد على منهج الأصولي المنطقي في تحصيل القطعي مندي من أصول الشريعة - كما سيتبين في المقدمة الثالثة. 
أما عن الحجة التي استند عليها الشاطبي في تقريره السابق فهو طريق السبر والتقسيم لأصول أدلة الشريعة المعتمد عليها في الاستنباط والاجتهاد ونبذ ما يتوهم في دخول ما ليس منها فيقسمها إلى ثلاثة أدلة قطعية رئيسة ترجع مقدمات الاستدلال لها: وهي "إما عقلية، كالراجعة إلى أحكام العقل الثلاثة: الوجوب والجواز والاستحالة وإما عادية، وهي تتصرف ذلك التصرف...، وإما سمعية، وأجلها المستفاد من الأخبار المتواترة في اللفظ، بشرط أن تكون قطعية، أو من الأخبار المتواترة في اللفظ بشرط أن تكون قطعية الدلالة، أو من الأخبار المتواترة في المعنى، أو المستفاد من الاستقراء في موارد

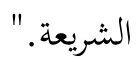

فنلاحظ من خلال سرد الشاطبي السابق لأصول أدلة الشريعة أن الأصول التي ذكرها كلها قطعية، ونلاحظ -أيضاً -عدم غفل الشاطبي لوسيلة الاستقراء التي تعرضت للإِهال من قبل الأصوليين والتي عليها جل الاعتماد في قطعية كثير من أصول الشريعة. وفي هاية المقدمة لم يفت الشاطبي أن ينبه طالب العلم للتفرقة بين الأصول الفقهية وبين الفروع النابحة بالاجتهاد عن تلك الأصول لأن القطعية لا تستقيم له إذا أدخلنا الفروع الفقهية النابحة عن أصول الفقه بأن يقال هذا الحكم فرض، أو مندوب، أو مباح، أو مكروه، أو حرام، فلا مدخل له في مسائل الأصول 
من حيث هي أصول. فمن أدخلها فيها فمن باب خلط بعض العلوم بعض.

\section{المقدمة الثالثة: في تطبيق قطعية أصول الفقه}

هذه المقدمة جاءت تلبي المطلب الأساسي لقطعية أصول الفقه والمقدمتان

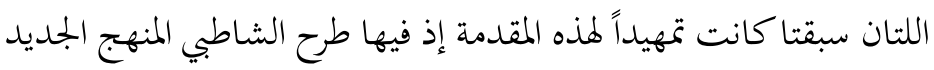

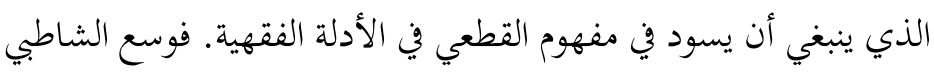
من مفهوم القطعي في الشريعة فقبل أن يتطرق الشاطبي إلى الموضوع نبّه بئه

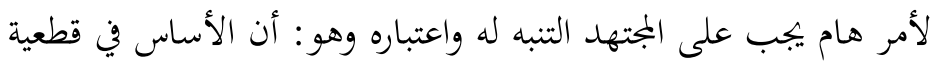

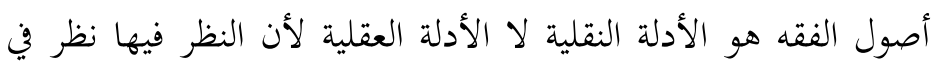
أمر شرعي، والعقل ليس بشارع.

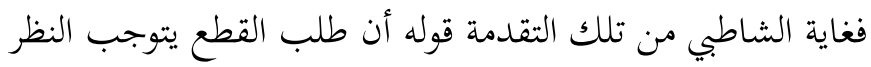

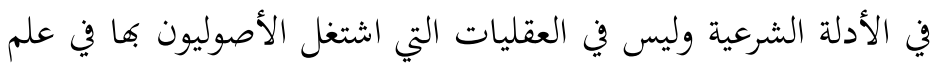

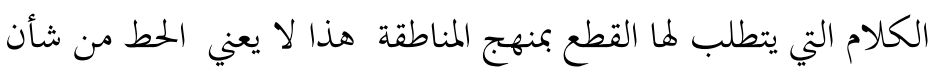

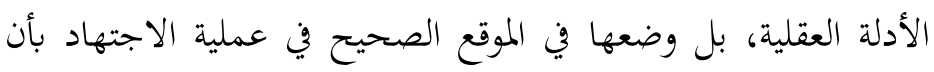

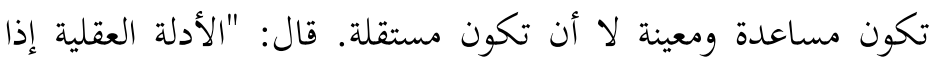

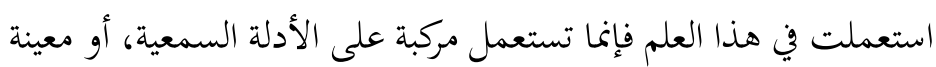

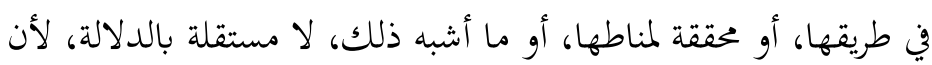
النظر فيها نظر في أمر شرعي.."

$$
\begin{aligned}
& 17 \text {-الموافقات، عب-هم. الجزء الأول بتصرف في العبارة. } \\
& \text { IV - - الموافقات. نفس المرجع السابق. }
\end{aligned}
$$


وانتقد الشاطبي في هذه المقدمة منهج القطع عند الأصوليين

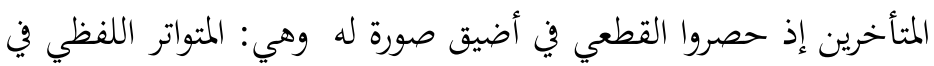

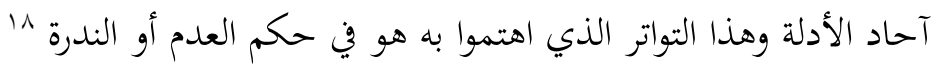

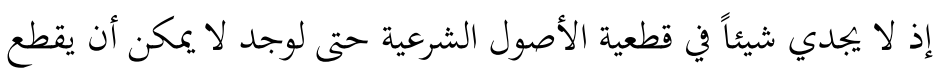
بمراده لتوقف فهمه على أدوات الاجتهاد الظنية يقول الشاطبي:

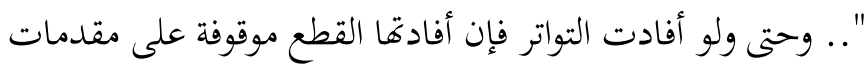

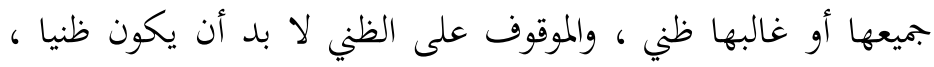

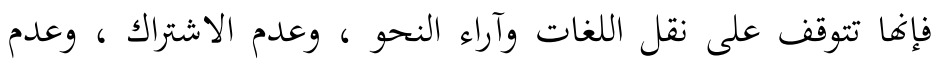

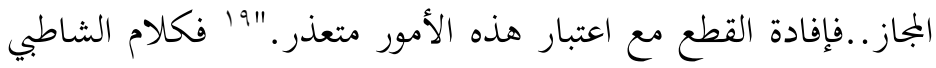
السابق فيه إثارة ظاهرة إلى مسلك الرازي الذي قاد الظنية في اللغويات.

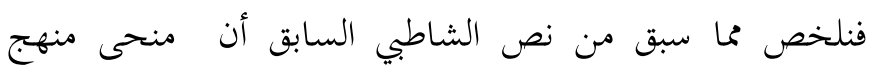

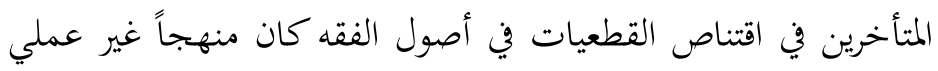

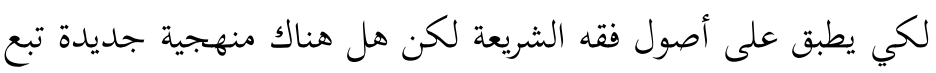

11 - مما يدعم قول الشاطبي السابق ما قاله عبدالعلي نظام الدين من أن "المتواتر من

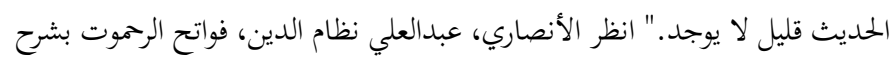

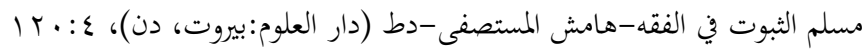

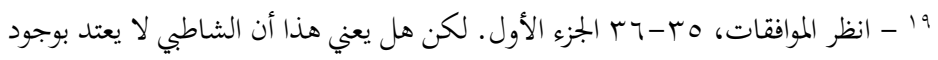

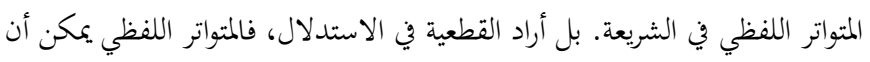

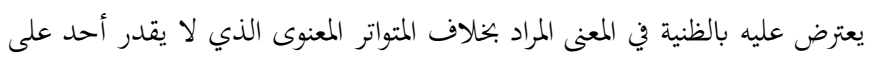
طعن في المعنى المراد فيه. 
لطرح أصول فقهية تبنى على القطعي ويمكن أن تقف في وجه اعتراضات الأدلة التي أقام صرحها علم المنطق؟

فني السطور الآتية سوف نرى فيها كيف أسس الشاطبي منهجيته الجديدة في بناء أصول فقه قطعية يعمل بها في أصول وفروع الشريعة، ولا تكون ظنية المعنى. قال "وإنما الأدلة المعتبرة هنا المستقرأة من جملة أدلة ظنية تضافرت على معنى واحد حتى أفادت فيه القطع، فإن للاجتماع من القوة ما ليس للافتراق. ولأجله أفاد التواتر القطع. وهذا نوع منه. فإذا حصل من استقراء أدلة المسألة مجموع يفيد العلم فهو الدليل

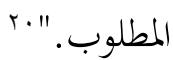

ولم يفت الشاطبي أن ينّظر هذا المنهج من ناحية الأصولية السلفية'r إذ أرجعها إلى الشبيه بالمتواتر المعنوي الذي مثّل له بالعلم بشجاعة علي رضي الله عنه، المستفاد من كثرة الوقائع المنقولة عنهم ومن هذا الطريق ثبت وجوب القواعد الخمس كالصلاة، والزكاة، وغيرها قطعاً، وإلا فلو استدل مستدل على وجوب الصلاة بقوله تعالى "أقيموا الصلاة" أو ما أشبه ذلك لكان الاستدلال بمجرده فيه نظر من أوجه لكن لما حفّ هذا

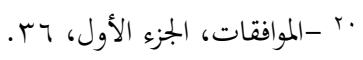

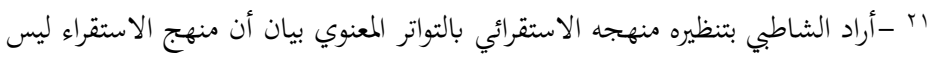

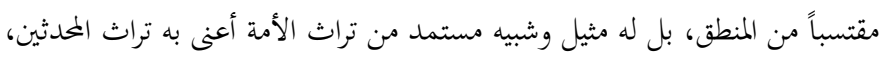

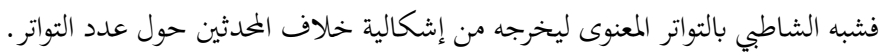


الدليل من الأدلة الخارجية والأحكام المترتبة عليه صارت الصلاة ضرورة في الدين لا يشك فيه إلا شاك في أصل الدين.

ويقرب الشاطبي منهجه بضرب أمثلة تطبيقية عن أصل الإجماع فهذا الأصل الهام من أصول الفقه ما اعتمد إلا من ذلك المسلك الاستقرائي وذلك أنه لو أخذ على انفراد كل دليل على حدة لما حصل القطع بل حصل الشك و التوهين ولم يفت الشاطبي بيان أن ذلك المسلك هو المنهج نفسه المتبع في بيان الأدلة في الموافقات فيقول: "ومن هنا اعتمد الناس في الدلالة على وجوب مثل هذا على دلالة الإجماع لأنه قطعي وقاطع لهذه الشواغب .وإذا تأملت أدلة كون الإجماع حجة أو خبر الواحد أو القياس حجة فهو راجع إلى هذا المساق ، لأن أدلتها مأخوذة من مواضع تكاد تفوت الحصر ، وهي مع ذلك مختلفة المساق لا ترجع إلى باب واحد ، إلا أها تنتظم المعنى الواحد الذي هو المقصود بالاستدلال عليه ، وإذا تكاثرت على الناظر الأدلة عضد بعضها بعضا فصارت بمجموعها مفيدة للقطع ، فكذلك الأمر في مآخذ الأدلة في هذا الكتاب .وهي مآخذ الأصول"r"r. فنقرر مما مضى: أن المتواتر المعنوى أقوى دليل قطعي يمكن أن يقف في وجه التشكيك والتوهين في دلالة النصوص و بقوة المتواتر اللفظي إذ يمكن لأهل التشكيك أن يشكوا في دلالة أحد الأدلة ولكن هل يمكنهم

r - - الموافقات، rVYr. بعض التصرف للتوسع انظر بداية الرسالة في منهجية الإمام في الموافقات. 
أن يشككوا في مجموعة كبية من الأدلة أفادت معنى واحداً؟ فإذا كان الجواب بلا فأن للاجتماع ما ليس للافتراق فكان حتماً على الأصوليين اتباع تلك المنهجية في النظر إلى أدلة الشريعة وأصولها وتطبيقها عملياً عند الاستدلال والتنويه عليها عند التأصيل لأن فائدقا العملية كبيرة سواء في أصول الشريعة أو فروعها.

أهمية مسلك التواتر المعنوي في قطعية الأصول عند الشاطبي مع التنبيه على أهميته في الفكر الإنساني

بعد عرض الشاطبي منهجيته الجديدة في النظر إلى أدلة الشريعة وأصولها تطرق إلى أمر هام بشأن النظر في منهجية قطعية الأصول فنبه إلى أن إندائن

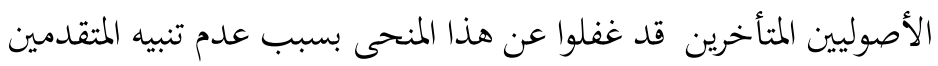

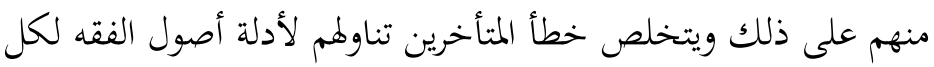

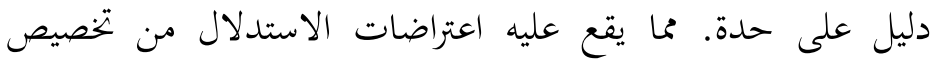

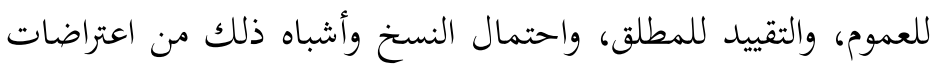

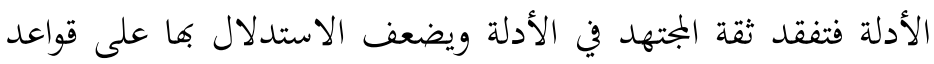

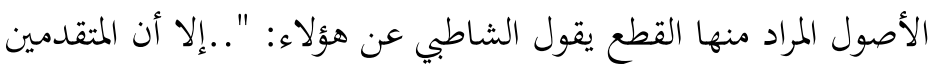

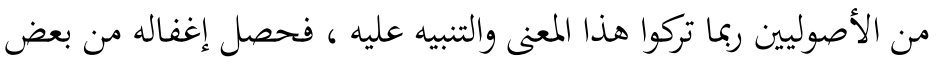

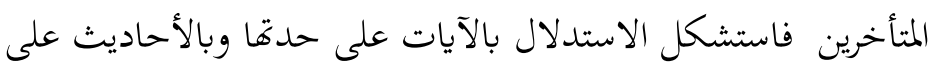

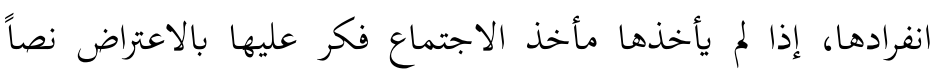

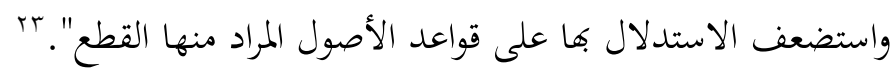


فتحذير الشاطبي من خطورة هذا المنهج صريح إذ لو اتبع لأدى إلى التشكيك ليس بأصول الفقه فحسب، بل في كليات الشريعة ولم يجصل لنا قطع بحكم شرعي ألبتة إلا أن نتهج منهج الاستقراء. إذ بفضل ذلك المنهج "الاستقرائي" استطاع السابقون أن يستنبطوا الضروريات الخمس: الدين، والنفس، والنسل، والمال، والعقل فهي "لم تثبت لنا بدليل معين، ولا شهد لنا أصل معين يمتاز برجوعها إليه، بل علمت ملاءمتها للشريعة بمجموع الأدلة لا تنحصر في باب واحد، ولو استندت إلى شيء معين لوجب عادة تعيينه ،وأن يرجع أهل الإجماع إليه، وليس كذلك. لأن كل واحد منها بانفراده ظني، ولأنه- كما لا يتعين أو غيره أن يكون المفيد للعلم خبر واحد دون سائر الأخبار - كذلك لا يتعين هنا، لاستواء جميع الأدلة في إفادة الظن على فرض الانفراد، وإن كان الظن يختلف باختلاف أحوال الناقلين، وأحوال دلالات المنقولات، وأحوال الناظرين في قوة الإدراك وضعفه، وكثرة البحث وقلته، إلى غير ذلك."أب وأيضاً لو لم يتبع ذلك المنهج الاستقرائي لما تميزت الأصول من الفروع فإن الفروع مستندة إلى آحاد الأدلة وإلى مآخذ معينة، فبقيت على أصلها من الاستناد إلى مئل الظن، بخلاف الأصول فإنها مأخوذة من استقراء مقتضيات الأدلة بإطلاق لا من آحادها على الخصوص. ro. 
فذلك النص المقتضب كان بياناً وافيا لمسلك التواتر المعنوي الذي يتكون من شتى نصوص وإن اختلفت قوتما ودرجتها ولكنها كانت كلها

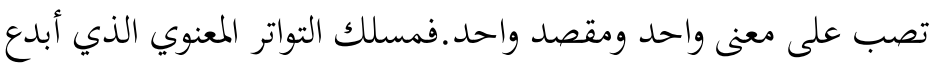
الشاطبي في إخراجه للأمة يصلح أن يكون معيارا جديدا للعلوم الإنسانية

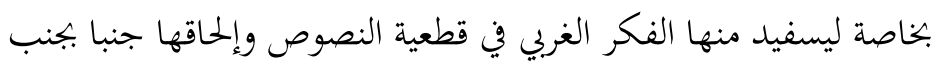

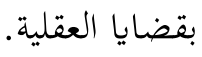
والتواتر المعنوي دليل آخر على قدرة منهجية المعرفة الإسلامية السلفية على إضغاء القطعية في اللغويات بخاصة إن المعارف الإنسانية

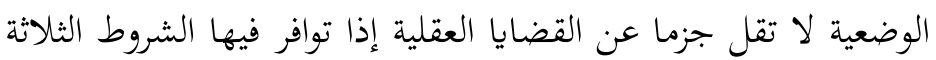

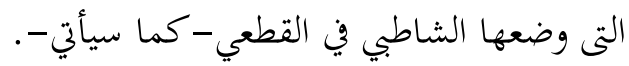
ولما كان منهج الشاطبي تطبيقياً وعملياً استعان بالأمثلة التطبيقية سئية

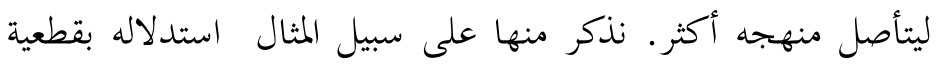
الأمر بالصلاة فقال: "فنحن إذا نظرنا في الصلاة فجاء فيها "أقيموا

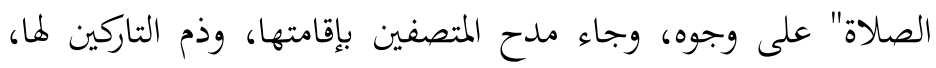

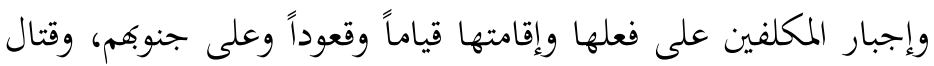

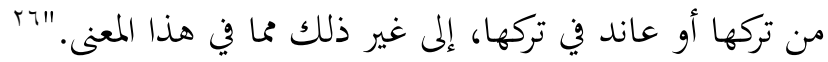
نلاحظ ما مضى من استدلال الشاطبي على قطعية وجوب الصلاة

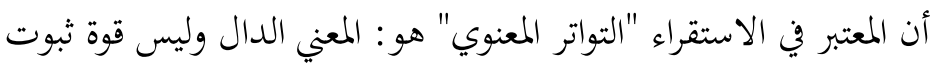

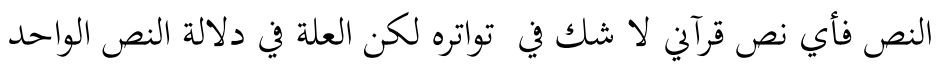


على المعنى القطعي. وهذا يؤكد صحة مسلك الشاطبي الاستقرائي وقربه من الواقع و تطبيقيه عليه. خلاف من يعتمد على التواتر اللفظي الذي لا يكفي الفرد منه للقطع إلا إذا تواتر على معنى واحد وهو غير واقع في

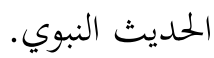

\section{أثر منهج التواتر المعنوي في تناول قطعية أصول مختلف فيها} هذا المبحث أرى أن يعد الثمرة الحقيقية لغرض الشاطبي من المقدمات الثلاث ففيه نتبين أنه بفضل منهجية الاستقراء (التواتر المعنوي) لأدلة أصول الشريعة تمكن الشاطبي من تحقيق قطعية بعض الأصول المختلف لهن في مشروعيتها فبعد عقد الشاطبي لمقدماته الثلاث نزع إلى عقد فصل تطبيقي في كيفية تحقيق النظر في شتى الأدلة الأصولية على منهج القطعية خاصة الأصول التي اختلف في صحتها كالمصالح المرسلة والاستحسان. فيحل الشاطبي هذه الإشكالية بفضل هذه المنهج المستمد من استقراء

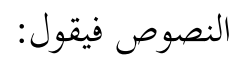

"ويبني على هذه المقدمة آخر، وهو أن كل أصل شرعي لم يشهد له نص معين، وكان ملائماً لتصرفات الشرع ومأخوذا معناه من أدلته، فهو صحيح يبنى عليه، ويرجع إليه، إذا كان ذلك الأصل قد صار بمجموع أدلته مقطوعاً به. لأن الأدلة لا يلزم أن تدل على القطع بالحكم بانفرادها دون غيرها إليها كما تقدم، لأن ذلك كالمعتذر ويدخل تحت هذا ضرب الاستدلال المرسل الذي اعتمده مالك والشافعي، فإنه وإن لم يشهد للفرع أصل معين فقد شهد له أصل كلي، والأصل الكلي إذا كان قطعياً قد 
يساوي الأصل المعين، وقد يربي عليه بحسب قوة الأصل المعين وضعفه، كما أنه قد يكون مرجوحاً في بعض المسائل حكم سائر الأصول المعينة المتعارضة في باب الترجيح، وكذلك أصل الاستحسان على رأي مالك

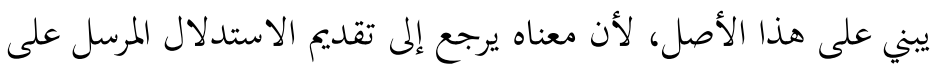
القياس.

فبهذه النظرة الواسعة في عموم أدلة الشريعة ندرك أن تلك الأصول المختلف في بعضها لم تبن على الظن والهوى، بل بنيت على أصول الشريعة الكلية المستقرأة فالنظرة الجزئية الحرفية في نصوص الشريعة تؤدي إلى نظر جزئي حرفي لا يستوعب باقي أدلة الشريعة. فعلى الناظر في الشريعة أن يكون محيطاً بجميع أدلة الشريعة ولا يقصر نظره على نص من النصوص لكيلا ينكر ما أثبته الآخرون.

\section{المقدمة السادسة: المقارنة بمنهجية تعاريف الألفاظ}

هذه المقدمة تعد من أهم المقدمات التجديدية في علم أصول الفقه ذلك أك أكس أن المقدمة تندرج في تنقية علم الأصول فيما علق به من آثار المنطق في التعاريف والمصطلحات الشرعية فبادئ ذي بدء بّين الشاطبي أن هناك منهجان لمعرفة التعاريف والتصديقات: الأول: المنهج النبوي في بيان الألفاظ وهو منهج موافق لمقاصد وروح الشريعة وواقع الأمة في بيان الألفاظ والتعاريف بالألفاظ المترادفة 
والتقريبات اللفظية دون الخوض في طلب ماهية الأشياء. ومن مميزته أيضاً- سهل الفهم لا لبس فيه ولا تعقيد في مخاطبة جمهور الأمة. الثاني: منهج المناطقة في طلب معرفة الألفاظ والأدلة بالخوض في ماهيتها والتعمق في كيفيتها وهذا المنهج صعب المرام لا ثمرة عملية من وراء البحث فيها لأها بحكم المتعذر لأن الأشياء لا تعرف على حقيقتها إذ الجواهر لما فصول ججهولة.

وخير دليل مثّل به الشاطبي للفرق بين المنهجين ما ذكره في تعريف معنى الملك فمعنى الملك عند أصحاب المسلك الأول خلق من خلق الله يتصرف في أمره. وعند أصحاب ابحاه المسلك الثاني يكون: جوهر بسيط ذو هاية ونطق عقلي أو ماهية بجردة عن المادة أصلاً .فواضح لكل ذي

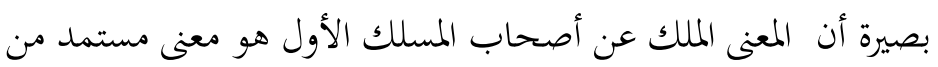
الشريعة وروح لغتها بخلاف المعنى عند أصحاب المسلك الثاني فهو خارج عن لغتها و ثقافتها وأساليبها.

ففي هذه المقدمة نستلهم منها موقف الشاطبي الصريح برفض استخدام مصطلحات المناطقة في أصول الفقه وإحلال مكاها المصطلحات الإسالامية العربية النابعة من الشريعة ولغتها. وعمل الشاطبي في ذلك الرجوع بعلم الأصول إلى ما كان عليه مؤسس علم الأصول الإمام الشافعي-رحمه الله- القائل: "ما جهل الناس ولا اختلفوا إلا لتركهم 
لسان العرب وميلهم إلى لسان أرسطاليس." "جغ فغرض الشاطبي من هذه المقدمة واضح هو الرجوع بعلم الأصول إلى مصادره الأصلية و البرهنة بالأدلة والأمثلة التطبيقية أن التعاريف و النابعة من الشريعة ولغتها هي أقوم وأقرب إلى العلم العملي التي تقوم عليه روح الشريعة.

\section{خصائص القطعي في الثريعة ومقارنتها بالمنهج الفلسفي}

لما كان منهج الإمام الشاطبي -رحمه الله- قائماً على وضع المعالم و الضوابط. حدد خصائص القطع لتعرف وتميز عن غيرها فجعل لها ثلاث خصائص:

الخصيصة الأولى: العموم والاطراد. لا عجب أن تأتي هذه الخصيصة من صلب مقاصد التكليف في الشريعة المبني على القطع. قال الشاطبي: "إحداها العموم والاطراد، فلذلك جرت الأحكام الشرعية في أفعال المكلفين على الإطلاق، وإن كانت آحادها الخاصة لا تتناهى، فلا عمل يفرض، ولا حركة، ولا سكون يدعى، إلا والشريعة عليه حاكمة إفراداً وتركيبا، وهو معنى كوها عامة." لكن ماذا عن خصوصيات كثير من الأحكام في الشريعة هل تخرج تلك الأحكام العموم والاطراد؟ يقرر

9r - -عقب الدكتور النجار على قول الشافعي بقوله "وواضح أن هذا النقد يشير إلى قيام

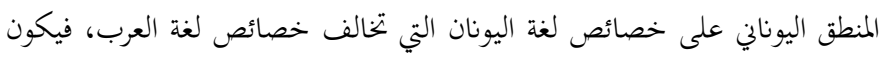

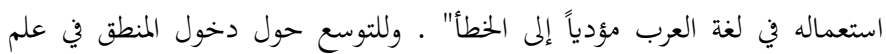

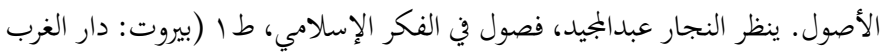


الشاطبي تماسك أحكام الشريعة ورجوعها إلى حلقة محكمة وإن تخصيصها لا ينفي عموميتها فيقول: "وإن فرض في نصوصها أو معقولها خصوص ما فهو راجع إلى عموم، كالعرايا، و القراض وأشباه ذلك فإنها راجعة إلى أصول حاجية أو تحسينية أو ما يكملها. وهي أمور عامة. فلا خاص في الظاهر إلا وهو عام في الحقيقة."r وتتجلى أهمية هذه الخصيصة حين التعارض والترجيح فلا يعارض بين ما ورد عاماً لجميع المكلفين ومستنده القطع وبين ما هو خاص لا يرتقى سنده عن الظنية. الخصيصة الثانية: الثبوت من غير الزوال. وهذه المزية تتجلى في تقوية الحكم القطعي من عوامل السلب للحكم الشرعي فلا يمكن أن تتعرض ما تتعرض له الأحكام الأخرى" فلذلك لا تعد فيها بعد كمالها نسخاً، ولا تخصيصاً لعمومها، ولا تقييداً لإطلاقها، ولا رفعاً لحكم من أحكامها، لا بحسب عموم المكلفين، ولا بحسب خصوص بعضهم ولا بحسب حال دون حال." آب هي صارت بسبب تلك القطع ركناً من أركان التكليف فهي" ما أثبت سبباً فهو سبب أبداً لا يرتفع، وما كان شرطاً فهو أبداً شرط وما كان واجباً فهو واجب أبداً، وهكذا جميع الأحكام. فلا زوال

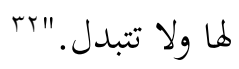

$$
\begin{aligned}
& \text {. r. }
\end{aligned}
$$

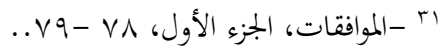

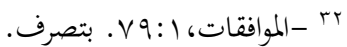


الخصيصة الثالثة: كون العلم حاكماً لا محكوماً. بمعنى كونه مفيداً العمل بما دلت عليه من بديهي أن يكون القطعي دالاً على العمل، بمعنى

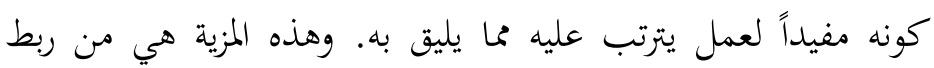

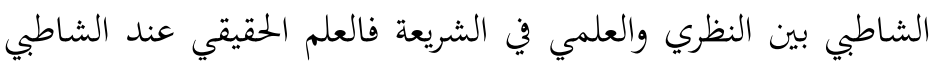
هو الذي تخرج منه بثمرة عملية وإلا كان الخوض فيما لا فائدة فيه. بكذه الخهي الخصائص الثلاث جعل الشاطبي أدلة الشريعة قطعية الدلالة موازية للأدلة

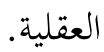

ربط الأستاذ عبد الجليل بادو خصائص القطعي عند الشاطبي

بالأوليات العقلية إذ فسر هذه الخصائص على المنهج الفلسفي فقال:

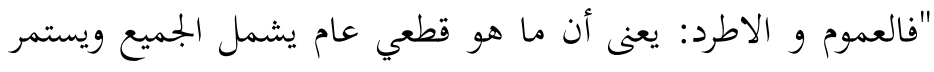

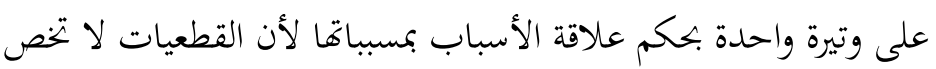

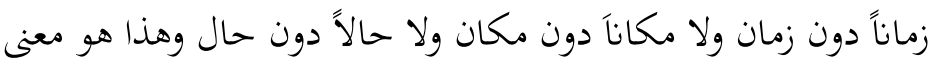

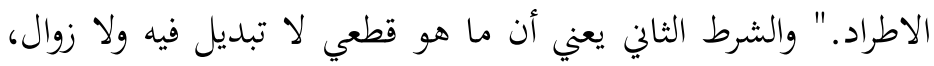

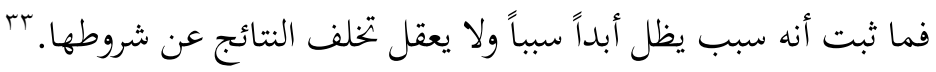

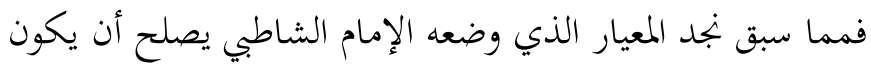

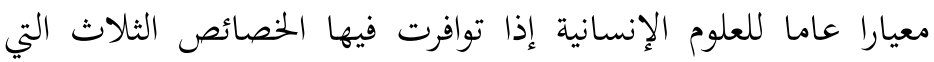
حددها الإمام الشاطبي.فما على فلاسفة اليوم إلا اختيار تلك الخصائص لتنزيلها على كافة العلوم الإنسانية.

rr - ينظر بادو عبدالجليل، أثر الشاطبي في الفكر السلفي بالمغرب، طا(الرباط: دار

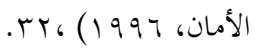




\section{أهم نتائج البحث والتوصيات}

1. إن أثر الفلسفة المنطقية على المنهج الاستدلالي الأصولي تتفاوت المبات

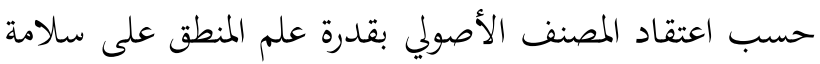

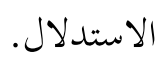

r. ب. بيان إن المنهح الاستدلالي الأصولي عند الرازي قد انطلق من مقتضيات فلسفة المنطق لا يحيد عنه إلا نادرا.

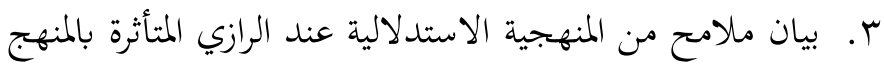
المنطقي التي جعلت أصول الفقه ظنية. ـ. نقد الإمام الشاطبي لمنهجية الإمام الرازي الفلسفية في كتاب

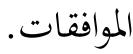

0. انبثت المنهجية الاستدلالية الأصولية عند الإمام الشاطبي ببيان

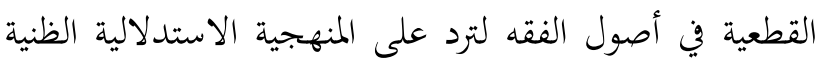
التي قادها الرازي في المحصول.

I. . من ابداعات منهجية المعرفة الإسلامية في علم أصول الفقه التي

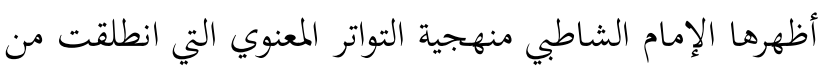

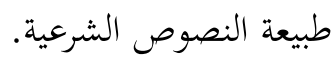
V. إن منهجية المعرفة الإسلامية في الاستدلال الأصولي عند الإمام الشاطبي قد أبدعت فهي أدخلت القطعي في مجال اللغويات فهي لا تقل قطعية عن القضايا العقلية. 


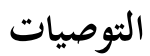

1. التوصية بمنهجية الإمام الشاطبي في التواتر المعنوي في الاستفادة

$$
\text { الفكر الغربي منها في بجال العلوم الإنسانية. }
$$

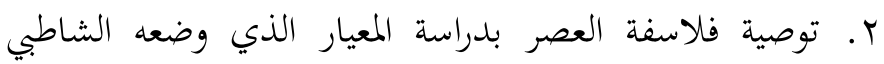
لتصبح معارف العلوم الإنسانية من الظنية إلى القطعية.

\section{المراجع}

الأنصاري، عبد العلي نظام الدين. فواتح الرحموت بشرح مسلم الثبوت في الفقه-هامش المستصفى. بيروت: دار العلوم، د.ت.

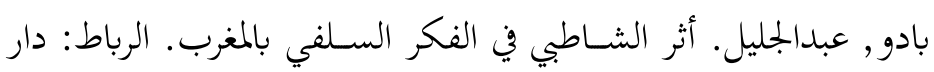

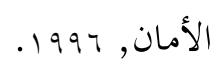

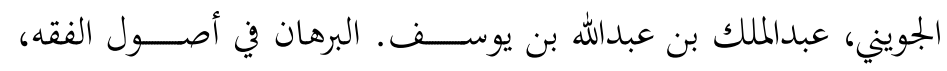

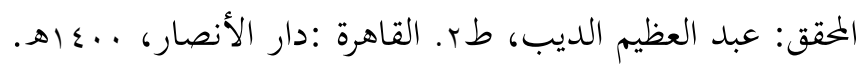

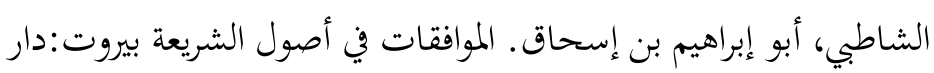

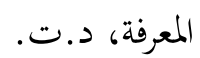

الرازي ، فخر الدين محمد بن عمر. المعالم في علم أصول الفقه، المققان:

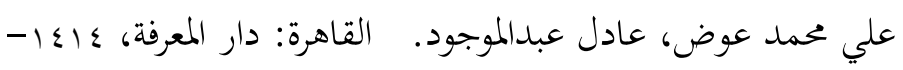
$.199 \varepsilon$

الغزالي، محمد بن محمد. المستصفى، المحقق: محمد عبدالسلام. بيروت:

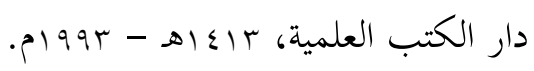




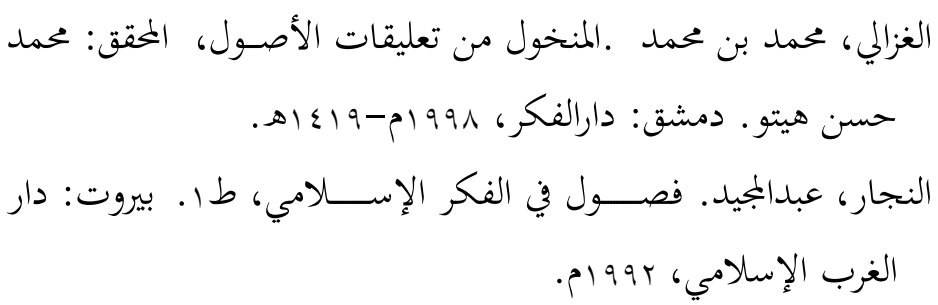

\section{References}

Al-Anșāìi, ‘Abd al-`Ali Niẓām al-Dīn. Fawātih al-Raḥmūt bi Sharh Muslim al-Thubūt fī al-Fiqh - Hāmish al-Mustașfā. Beirut: Dār al-'Ulūm, n.d.

Bādū, 'Abd al-Jalīl. Athar al-Shāțibi fí al-Fikr al-Salafï bi alMaghrib. Ribath: Dār al-Amān, 1996.

Al-Juwayni, `Abd al-Malik b. `Abdullāh b. Yūsuf. Al-Burhān fì Usūl al-Fiqh, tahqiq by `Abd al-`Aẓim al-Dīb. Cairo: Dār al-Anșār, $1400 \mathrm{H}$.

Al-Shāṭibī, Abū Ibrāhīm b. Isḥāq. Al-Muwāfaqāt fī Ușūl alSharìah. Beirut: Dār-al-Ma`rifah, n.d.

Al-Rāzìi, Fakhr al-Dīn Muhammad b. 'Umar. Al-Ma ālim fī 'Ilm Ușūl al-Fiqh, tahqiq by 'Alì Muhammad 'Iwad and `Ādil `Abd al-Mawjūd. Cairo: Dār al-Ma`rifah, 1994.

Al-Ghazālì, Muḥammad b. Muḥammad. Al-Mustaşfā, tahqiq by Muḥammad `Abd al-Salām. Beirut: Dār al-Kutub al'Ilmiyyah, 1993.

Al-Ghazālì, Muḥammad b. Muḥammad. Al-Mankhūl min Ta lìqāt al-Ușūl, tahqiq by Muhammad Hassan Hitou. Damascus: Dār al-Fikr, 1998.

Al-Najjār, `Abd al-Majìi. Fuṣūl fī al-Fikr al-Islāmī. Beirut:

Dār al-Gharb al-Islāmí, 1992. 